\title{
STRAT: An Automated Algorithm to Retrieve the Vertical Structure of the Atmosphere from Single-Channel Lidar Data
}

\author{
Y. MORILLE \\ Laboratoire de Météorologie Dynamique, Institut Pierre-Simon Laplace, Palaiseau, France \\ M. HAEFFELIN \\ Institut Pierre-Simon Laplace, Palaiseau, France \\ P. DRobinski AND J. Pelon \\ Service d'Aéronomie, Institut Pierre-Simon Laplace, Paris, France
}

(Manuscript received 28 March 2006, in final form 18 August 2006)

\begin{abstract}
Today several lidar networks around the world provide large datasets that are extremely valuable for aerosol and cloud research. Retrieval of atmospheric constituent properties from lidar profiles requires detailed analysis of spatial and temporal variations of the signal. This paper presents an algorithm called Structure of the Atmosphere (STRAT), which is designed to retrieve the vertical distribution of cloud and aerosol layers in the boundary layer and through the free troposphere and to identify near-particle-free regions of the vertical profile and the range at which the lidar signal becomes too attenuated for exploitation, from a single lidar channel. The paper describes each detection method used in the STRAT algorithm and its application to a tropospheric backscatter lidar operated at the SIRTA observatory, in Palaiseau, $20 \mathrm{~km}$ south of Paris, France. STRAT retrievals are compared to other means of layer detection and classification; retrieval performances and uncertainties are discussed.
\end{abstract}

\section{Introduction}

Remote sensing of the atmosphere by lidar dates from the 1960s. Lidars have since become very popular remote sensing tools. They are used extensively both in ground-based and airborne configurations to get detailed vertical profiles of cloud or aerosol properties, such as the extinction coefficient, to learn more about the nature of particles present aloft. Lidars are commonly deployed during intensive observation field experiments as well as for routine long-term monitoring.

Today several global and regional networks of atmospheric observatories exist that use lidars as their main monitoring instrument. The European Aerosol Research Lidar Network (EARLINET) monitors aerosol transport over Europe based on 21 Rayleigh/Mie and Raman lidar stations (Bösenberg et al. 2003). Similarly, the National Institute for Environmental Studies of Japan coordinates a network of 12 automatic dual-

Corresponding author address: Y. Morille, Laboratoire de Météorologie Dynamique, Institut Pierre-Simon Laplace, Ecole Polytechnique, 91128 Palaiseau CEDEX, France.

E-mail: morille@lmd.polytechnique.fr wavelength polarization lidars continuously to study Asian dust transport (Shimizu et al. 2004). The continent between Europe and Asia is covered by the Commonwealth of Independent States-Lidar Network (CISLiNet) project that aims to monitor aerosol and ozone through a network of six lidar stations from Belarus, Russia, and the Kyrgyz Republic since the beginning of 2004. Building from the research capabilities already established at a number of eastern North America lidar facilities, a Regional East Atmospheric Lidar Mesonet (REALM) has been proposed to monitor air quality in the vertical from multiple locations in that region (Hoff and McCann 2002). The National Aeronautics and Space Administration funds a MicroPulse Lidar Network (MPLNet; Welton et al. 2001) to monitor troposheric aerosols based on 20 micropulse lidars located at climatologically diverse locations on the planet and coordinated with the Aerosol Robotic Sunphotometer Network (AERONET). The Network for the Detection of Stratospheric Change (NDSC) monitors stratospheric ozone using lidars that range through the stratosphere.

Continuous or routine operations of such systems produce upward of 1000 vertical profiles per day for

DOI: 10.1175/JTECH2008.1

(C) 2007 American Meteorological Society 
each channel of each system. All systems produce fundamental information about the structure of the atmosphere, which is the vertical distribution of the particle layers from near the ground to the top of the lidar range. Those are basic parameters, yet our current understanding of the vertical distributions of cloud and aerosol layers in the atmosphere remains limited by lack of large-scale analysis of available datasets. Furthermore, in the context of new satellite missions carrying active remote sensing payloads, such as the Cloud-Aerosol Lidar and Infrared Pathfinder Satellite Observations (CALIPSO; Winker et al. 2003), groundbased lidar observatories have an increasingly important role to play in establishing regional climatologies that will tie in the temporally sparse global-scale satellite measurements.

The need for robust algorithms designed to process large lidar datasets has been established for over a decade (e.g., Platt et al. 1994). Several authors have exploited long-term lidar datasets to derive statistics and climatologies of cloud and aerosol macrophysical properties (e.g., Cadet et al. 2003; Comstock et al. 2002; Sassen and Campbell 2001). In such analyses, particle layers, being clouds or aerosols, are typically detected using slope change in the lidar profile (e.g., Flamant et al. 1997; Shimizu et al. 2004), or comparing the lidar power return to an expected clear-sky value (e.g., Clothiaux et al. 1998). Several authors developed methods using wavelet transforms to identify particle layers in the lidar profile (e.g., Cohn and Angevine 2000; Brooks 2003), but those studies were limited to boundary layer height (BLH) analyses.

In this paper we present an end-to-end algorithm designed to retrieve an ensemble of basic parameters of the particulate atmosphere from single-channel lidar profiles. The algorithm is designed with modules that retrieve the height of the boundary layer, the vertical distribution of particle layers (clouds and aerosols), and that identify layers that are near particle free. Each retrieval taken independently is not new; however, the added value comes from the use of multiple analyses on each lidar backscatter profile to derive a self-consistent classification. The specifications of this algorithm are as follows:

- to detect all particle layers from near the ground to the top of the lidar range, that is, cloud and aerosol layers in the free troposphere and the vertical extent of the boundary layer (BL) from the raw uncalibrated lidar backscatter profile;

- to identify pristine layers predominantly populated by molecules, and hence considered as near particle free, so that the lidar signal can be calibrated (with respect to a calculated molecular backscatter) in an automated manner for further inversion of the signal;

- to be widely applicable to any single- or multiwavelength ground-based lidar system (micro- to millijoule pulse energy, high or low pulse frequencies, UV, visible, and near-infrared wavelength) by using the signal-to-noise ratio (SNR) as the only threshold reference;

- to be automatic and robust so that long lidar time series can be processed in an operational environment.

The objective of this algorithm development is to provide a tool that can be used to process large groundbased lidar datasets and hence give access to a very detailed macrophysical classification of the particulate atmosphere. This is the first and necessary step toward extending regional statistics of cloud and aerosol macrophysical properties.

In section 2, we present the lidar measurement dataset used to develop the STRAT algorithm. Section 3 is dedicated to the description of the algorithm and section 4 to the evaluation of the algorithm. Conclusions are provided in section 5 .

\section{Data description}

To develop the Structure of the Atmosphere (STRAT) algorithm we use a database produced by the Site Instrumental de Recherche par Télédetection Atmosphérique (SIRTA) observatory, a facility dedicated to observing the atmosphere in support of cloud and aerosol research. SIRTA is located in Palaiseau, $20 \mathrm{~km}$ south of Paris, France; the data can be retrieved through its Web site (www.sirta.fr). SIRTA gathers active and passive remote sensing instruments to retrieve optical, radiative, and dynamic properties of the atmosphere and its constituents. This includes a dualwavelength polarization lidar, Lidar Nuages Aérosols (LNA; i.e, the Cloud Aerosol Lidar), a millimeter-wave Doppler radar, a near-IR ceilometer, a surface broadband flux station, and standard weather measurements (Haeffelin et al. 2005). The SIRTA database includes also radiosonde profile data produced by Météo-France $15 \mathrm{~km}$ from the site as part of their national operational network (0000 and 1200 UTC).

The main dataset used to develop STRAT is that of the LNA. Table 1 lists its technical characteristics. LNA profiles corrected for electronic noise, atmospheric background signal, and range divergence are available in the SIRTA database in netcdf format for the period starting in March 2002 through today $(3000 \mathrm{~h})$. These level-1 files contain lidar backscatter profiles for six different channels (see Table 1) along with a quality 
TABLE 1. LNA description.

\begin{tabular}{ll}
\hline \hline Laser type & Nd:Yag \\
Emitted wavelengths & 532 and $1064 \mathrm{~nm}$ parallel polarized \\
Pulse energy & $160-200 \mathrm{~mJ}$ \\
Repetition rate & $20 \mathrm{~Hz}$ \\
Range resolution & $15 \mathrm{~m}$ \\
Detected wavelengths & $532 \mathrm{~nm}$ parallel polarized \\
& $532 \mathrm{~nm}$ cross polarized \\
& $1064 \mathrm{~nm}$ \\
Telescopes & Narrow field of view (NFOV) \\
& $\varnothing=60 \mathrm{~cm}$ \\
& $0.5 \mathrm{mrad}$ \\
& Wide field of view \\
& $\varnothing=20 \mathrm{~cm}$ \\
& $5 \mathrm{mrad}$ \\
\hline
\end{tabular}

flag that indicates when the SNR drops below 3 (see section 3a). Several studies (Hodzic et al. 2004; Naud et al. 2004; Chiriaco et al. 2004; Cadet et al. 2005; Mathieu et al. 2006) are based on this lidar dataset and the output of the STRAT algorithm described in this paper. The lidar signal analysis by STRAT makes use of density profiles derived from radiosounding data (temperature and pressure) to simulate the theoretical lidar backscatter solely due to molecules. Two radiosonde profiles per day are enough to capture most density profile variations.

In section 4 we use ceilometers measurements collocated with the LNA to perform comparisons of cloud detection and cloud-base height $(\mathrm{CBH})$ retrievals. The ceilometer uses a laser diode with an emitted wavelength of $855 \mathrm{~nm}$; its pulse repetition frequency is 6494 $\mathrm{Hz}$ with maximum emitted light power of $50 \mu \mathrm{W} \mathrm{m} \mathrm{m}^{-2}$ and its optical divergence is $1.2 \mathrm{mrad}$. Cloud information is retrieved through a Vaisala proprietary algorithm that looks for high backscatter values in the profile.

In section 4 we also compare STRAT retrievals of the boundary layer height with estimations based on potential temperature profiles. For that we derive highresolution $(10 \mathrm{~m})$ temperature and pressure profiles from the standard significant points provided in the Météo-France file.

\section{Algorithm description}

The STRAT algorithm includes four successive detections carried out on individual lidar profiles:

- noise detection, to identify where the lidar signal becomes too weak (signal-to-noise ratio) for further exploitation, so that data are not misinterpreted;

- molecular layer detection, to identify regions that are near particle free, that is, populated by molecules only or with a negligible concentration of particles, because lidar calibration is carried out in those re- gions by comparison with computed molecular backscatter profiles. (This will enable lidar data users to automate processes that require calibration such as inversion of extinction profiles or calculation of layer optical depth or investigation of cloud thermodynamic phase using depolarization ratio.);

- particle layer detection with separate cloud and aerosol layer identification, so cloud and aerosol processes can be studied;

- boundary layer detection, so boundary layer process studies can be addressed.

Finally, a flag variable is derived with value 0 for noise, 1 for molecular layers, 2 for boundary layer, 3 for aerosol layers, 4 for cloud layers, and 10 for unidentified layers. Figure 1 shows a diagram of the STRAT algorithm data processing.

\section{a. Noise detection}

\section{1) Method}

A simple signal-to-noise ratio threshold allows us to determine where the signal is too noisy to extract information from the lidar measurement. For each profile, it has been shown (Durieux and Fiorani 1998) that the noise level $\sigma(r, t)$ of the measured signal, assuming all its components are independent, can be written as

$$
\sigma(r, t)=\sqrt{\sigma_{\text {sig }}(r, t)^{2}+\sigma_{b}(r, t)^{2}+\sigma_{d}(r, t)^{2}},
$$

where $\sigma_{\text {sig }}(r, t)^{2}$ is the shot noise induced by and proportional to the backscattered lidar signal, $\sigma_{b}(r, t)^{2}$ is the shot noise resulting from background light, and $\sigma_{d}(r, t)^{2}$ is the shot noise resulting from the dark current.

Assuming that $\sigma_{\text {sig }}(r, t)^{2}, \sigma_{b}(r, t)^{2}$, and $\sigma_{d}(r, t)^{2}$ are proportional to the backscattered lidar power $P(r, t)$, to the background noise power $B_{b}(r, t)$, and to the dark current noise power $B_{d}(r, t)$, respectively, Eq. (1) becomes

$$
\sigma(r, t)=C \sqrt{P(r, t)+B_{b}(r, t)+B_{d}(r, t)},
$$

where $C$ is a proportionality coefficient to be determined. Assuming that $B(r, t)$, defined as the sum of $B_{b}(r, t)$ and $B_{d}(r, t)$, is constant along the profile, the noise level can be estimated at the altitude range where there is no lidar return $[P(r, t)=0]$ by computing the signal standard deviation $\sigma_{P=o}(r, t)$ of $P(r, t)$ at this range.

The proportionality coefficient $C$ can thus be estimated by averaging the ratio derived from Eq. (2) over a given number of points as

$$
C=\frac{\overline{\sigma_{P=0}(r, t)}}{\sqrt{B(r, t)}}=\frac{1}{N} \sum_{1}^{N} \frac{\sigma_{P=0}(r, t)}{\sqrt{B(r, t)}} .
$$




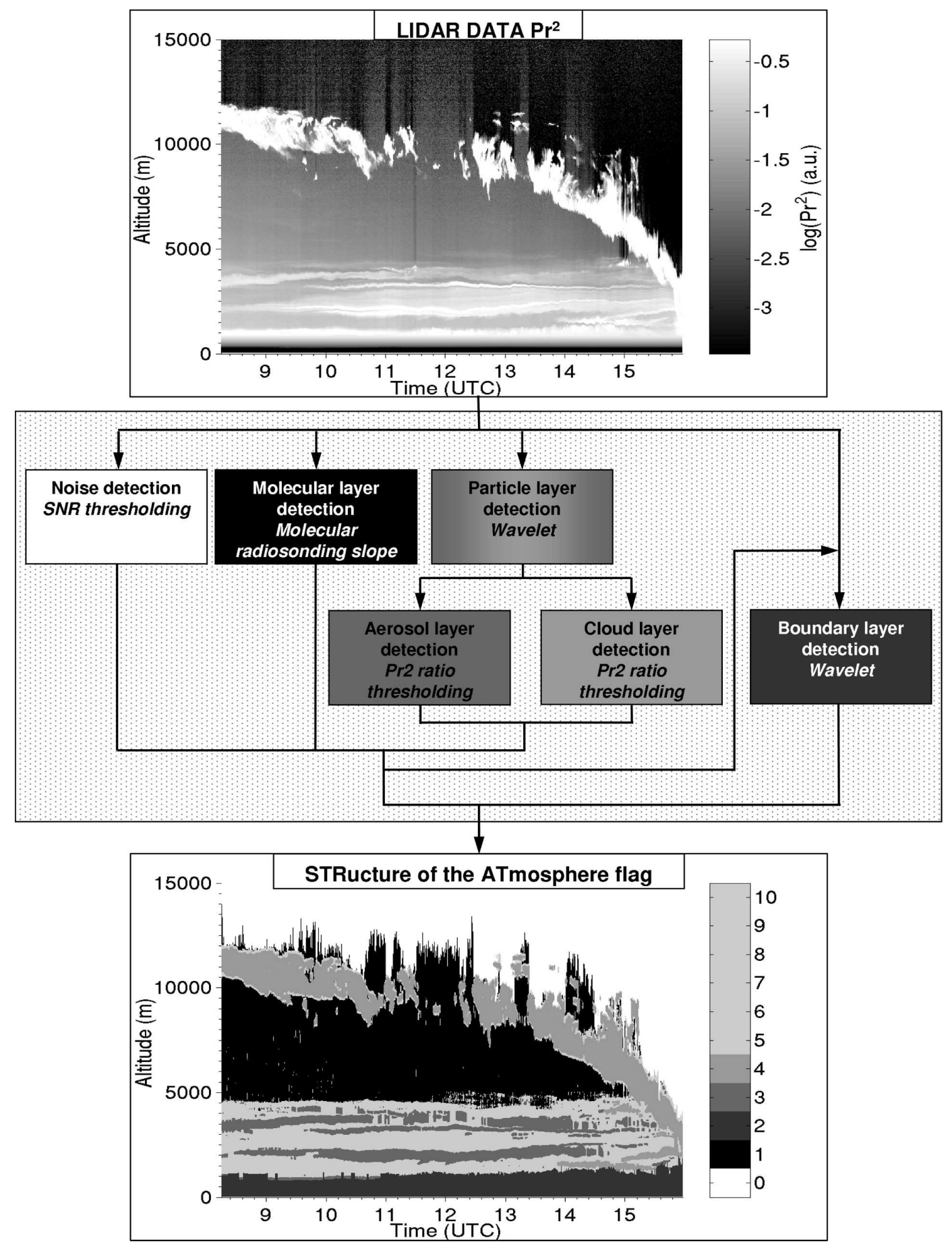

FIG. 1. STRAT algorithm diagram.

The noise level can then be expressed as

$$
\sigma(r, t)=\frac{\overline{\sigma_{P=0}(r, t)}}{\sqrt{B(r, t)}} \sqrt{P(r, t)+B(r, t)} .
$$

Hence the signal-to-noise ratio $\operatorname{SNR}(r, t)$ can be written as

$$
\operatorname{SNR}(r, t)=\frac{P(r, t)}{\frac{\sigma_{P=0}(r, t)}{\sqrt{B(r, t)}} \sqrt{P(r, t)+B(r, t)}} .
$$

Note that $C$ can also be derived from pretrigger data if available. This retrieval can be checked against the result of Eq. (3) for consistency. 


\section{2) Threshold DETERMinAtion}

In the STRAT algorithm, the signal is considered to be too noisy for further analysis when the SNR falls below a threshold of $T_{1}=3$. Indeed, for a Gaussian noise $99 \%$ of values are contained in the interval $\pm 3 \sigma_{P=0}(r, t)$. Boundary layers, molecular layers, and cloud and aerosol layers will be detected on the part of the signal that is above that threshold. For systems with a very low signal-to-noise ratio, the algorithm must be applied to time-averaged profiles.

Note that if $B(r, t)$ is large (e.g., daytime), $\sigma_{P=0}(r, t)$ can be used as the signal noise for convenience. This simplification does not introduce significant error in determining if $\operatorname{SNR}(r, t)$ is less or greater than 3, as for small SNR values $\sigma(r, t)$ is quite close to $\sigma_{P=0}(r, t)$ because $P(r, t) / B(r, t)$ tends toward 0 .

\section{b. Molecular layer detection}

\section{1) METHOD}

Identification of particle-free or near-particle-free layers is of particular importance, as they are often used in lidar calibration algorithms (e.g., Sassen et al. 1989; Platt 1979). For simplicity, these layers will be labeled as molecular layers although they may contain aerosols in small quantities (see section 4 a for discussion). The identification algorithm for molecular layers is based on analysis of the variability of the lidar signal around a theoretical molecular backscatter profile computed from pressure and temperature profiles. Thermodynamic profiles can be obtained from collocated atmospheric sounding measurements or extracted from model analysis data.

A normalization coefficient $K(r, t)$ is estimated at each range of the lidar signal as

$$
K(r, t)=\frac{\sum_{r^{\prime}=r-N}^{r+N} \frac{\beta_{\text {mol }}\left(r^{\prime}, t\right)}{\beta_{\text {lidar }}\left(r^{\prime}, t\right)}}{2 N+1}
$$

where

$$
\beta_{\text {lidar }}(r, t)=P(r, t) r^{2}
$$

is the nonnormalized attenuated backscatter coefficient, $\beta_{\text {mol }}(r, t)$ is the computed theoretical molecular backscatter coefficient, and $2 N+1$ is the size of the averaging window.

The variability, $V(r, t)$, of the normalized lidar signal around the molecular backscatter profile at a range $r$ is determined as
$V(r, t)=\frac{\sum_{r^{\prime}=r-N}^{r+N}\left\{\frac{1}{r^{\prime 2}}\left[\beta_{\text {lidar }}\left(r^{\prime}, t\right)-\frac{1}{K(r, t)} \beta_{\mathrm{mol}}\left(r^{\prime}, t\right)\right]\right\}^{2}}{2 N+1}$

where $K$ is the coefficient used to normalize the lidar profile to the molecular profile in the averaging window. A sensitivity study showed 20 gates (e.g., $300 \mathrm{~m}$ for the LNA) to be a wide enough averaging window to detect only atmospheric variations.

In molecular layers, the lidar backscatter signal $\beta_{\text {lidar }}(r, t)$ can be expressed as the sum of molecular backscatter $P_{\text {mol_lidar }}^{\prime}(r, t)$ and an additional zero mean noise $M(r, t)$ :

$$
\beta_{\text {lidar }}(r, t)=\left[P_{\text {mol_lidar }}^{\prime}(r, t)+M(r, t)\right] r^{2} .
$$

Hence, in molecular layers Eq. (8) becomes

$$
V(r, t)=\frac{\sum_{r^{\prime}=r-N}^{r+N}\left[M\left(r^{\prime}, t\right)\right]^{2}}{2 N+1} .
$$

The variability $V(r, t)$ is only due to the noise variability and hence can be compared to the noise variance $\sigma(r$, $t)^{2}$. So, a threshold value $V_{\text {thr }}(r, t)$ can be defined with respect to the noise variance $\sigma(r, t)^{2}$ as

$$
V_{\mathrm{thr}}(r, t)=T_{2} \sigma(r, t)^{2},
$$

where $T_{2}$ is the molecular layer threshold coefficient. Thus, if $V(r, t)$ is below the threshold value $V_{\text {thr }}(r, t)$, we consider the lidar backscatter power to be characteristic of a molecular layer.

\section{2) THRESHOLD DETERMINATION}

Here again we use $\sigma_{P=0}(r, t)$ as a substitute for $\sigma(r, t)$ because in molecular layers the two values are quite close. Indeed, in our case $P(r, t)$ is typically lower than the background backscatter $B(r, t)$ and hence $\sigma(r, t)$ tends toward $\sigma_{P=0}(r, t)$.

To determine this threshold, values of $V(r, t) / \sigma_{P=0}(r$, $t)^{2}$ [Eqs. (8) and (11)] have been computed from one profile per day over the available database (October 2002-October 2005) only on signal values when the SNR is greater than 3 .

Figure 2 illustrates the probability density function (PDF) of $V(r, t) / \sigma_{P=0}(r, t)^{2}$ at two wavelengths (532 and $1064 \mathrm{~nm}$ ) with $2 N+1=21$ gates $=315 \mathrm{~m}$. The PDF of the function $V(r, t)$ expressed in Eq. (10) is also represented in Fig. 2 with a solid line. The simulated noise used to estimate this PDF is a Gaussian noise similar to the real one.

Distributions are divided in two separate regions. 


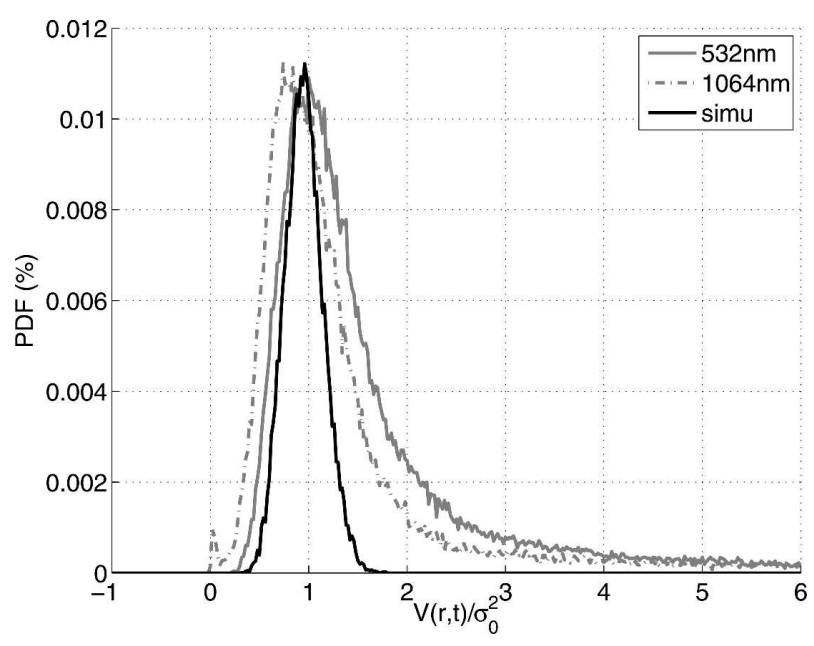

FIG. 2. PDF of $V(r, t) / \sigma_{0}(t)^{2}$ values estimated on one profile per day for the entire database at two wavelengths-532 (gray solid line) and $1064 \mathrm{~nm}$ (gray dotted line) - and PDF of simulated $V(r$, $t) / \sigma_{o}(t)$ values in molecular layers (black solid line) with $2 N+1=$ 21 gates $=315 \mathrm{~m}$.

The first one is a narrow Gaussian distribution ranging between 0 and 3. It can be associated with molecular layers where the variability is smaller than in particle layers. The second one is a very broad distribution of $V(r, t) / \sigma_{P=0}(r, t)^{2}$ with values greater than 3 . Because the objective is to use molecular layers for calibration, it is important not to falsely detect stable particle layers as molecular layers. For our application, a threshold value $V_{\mathrm{thr}}(r, t)$ of $3 \sigma_{P=0}(r, t)^{2}$ is a good compromise to separate molecular layers from other layers. The difference in distribution width between the 532- and 1064nm curves of Fig. 2 can be attributed to the signal quality of the two different channels.

\section{c. Cloud and aerosol layer detection}

\section{1) METHOD}

The majority of particle layer detection techniques described in the literature use thresholding tests on the first derivative of the backscatter intensity (e.g., Pal et al. 1992). Such methods give satisfying results as long as the signal-to-noise ratio remains high. Other techniques use algorithms that depend on cloud type (e.g., Chazette et al. 2001). While they are suited for case studies, they cannot be used for automated detection. In the STRAT algorithm, a combination of wavelet transform and $P r^{2}$ ratio thresholding is used to identify particle regions in lidar profiles.

The continuous wavelet transform (CWT) is used to detect discontinuities in the lidar signal as the base, the top, and the peak backscatter of individual particle lay-

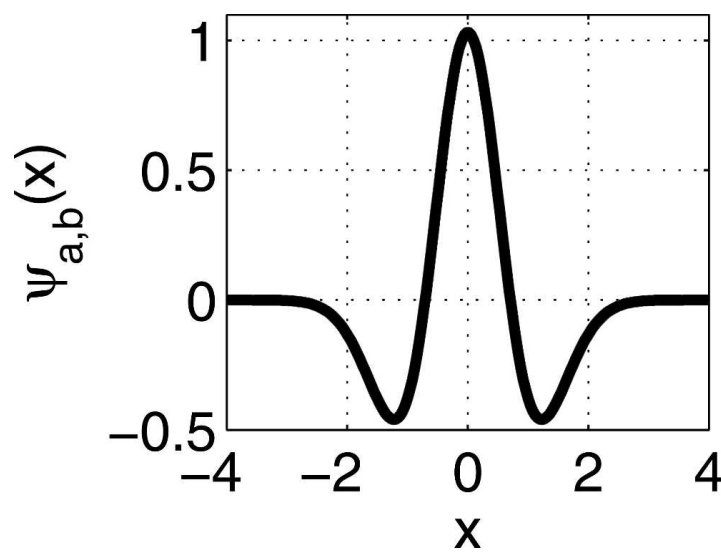

FIG. 3. Second derivative of a Gaussian wavelet called the Mexican hat wavelet.

ers. This method, based on seeking high correlation between the lidar signal and the wavelet characterized by the "Mexican hat" shape for each range and for each scale, is inspired by studies by Mallat and Hwang (1992) and an algorithm developed by Brooks (2003). The Mexican hat wavelet $\Psi(r)$, shown in Fig. 3, is the second derivative of a Gaussian. It is used because its shape is very similar to the shape of the lidar signal backscattered by cloud or aerosol layers. Additionally, "derivates of Gaussians are most often used to guarantee that all maxima lines propagate up to the finest scales" (Mallat and Hwang 1992), which is not the case of the Haar wavelet.

First, the CWT is computed for each $P(r, t)$ profile as

$$
\mathrm{CWT}_{a, b}(r, t)=\sum_{r} P(r, t) \psi_{a, b}(r),
$$

where

$$
\Psi_{a, b}(r)=\frac{1}{\sqrt{a}} \Psi\left(\frac{r-b}{a}\right),
$$

where $a$ is the wavelet dilation (or scale) and $b$ is the location of its center. CWT coefficients can be interpreted as a correlation coefficient between the wavelet (centered on $b$ and scaled by $a$ ) and the signal $P(r, t)$.

Second, the modulus of CWT coefficients is determined to extract the lines of modulus maxima of the $\mathrm{CWT}_{a, b}(r, t)$ that are lines (or ridges) formed by all maxima found at all dilations. This skeleton of the CWT, formed by all ridges, represents the highest correlation and anticorrelation between the signal $P(r, t)$ and the wavelet from the largest to the finest scale.

Figure 4 illustrates the performance of this method for an ideal cloud or aerosol backscatter profile (Fig. 4a) and a real one (Fig. 4d). Figure 4b and Fig. 4e show CWT coefficients for the ideal profile and the real one, 

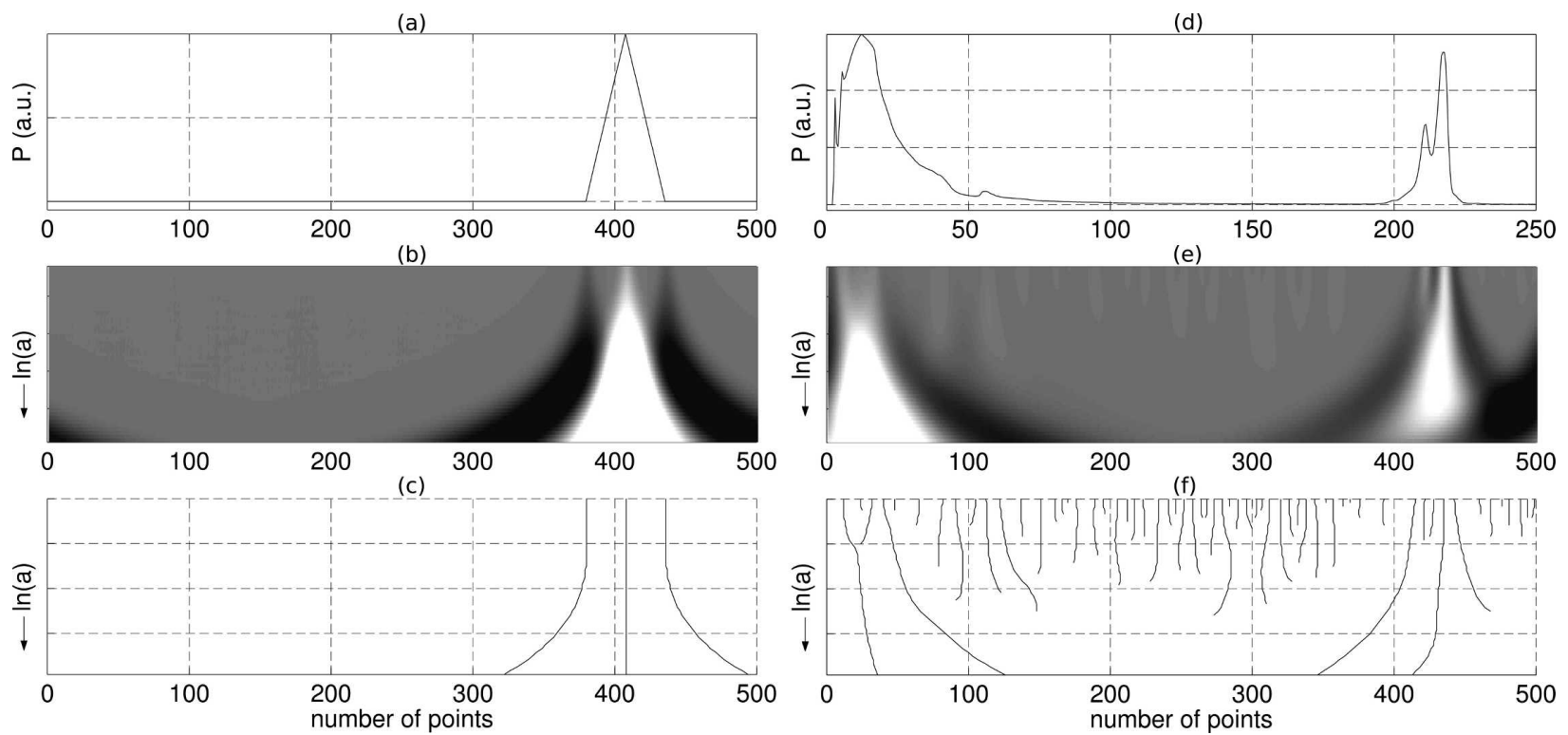

FIG. 4. (a) Simulated and not normalized backscattering power received for an ideal cloud or aerosol case in function of altitude; (b) corresponding CWT coefficients calculated for different dilation a (finest high up) and different location of wavelet's center $b$ with highest coefficients in white and lowest in black; and (c) skeleton (maxima lines) of the CWT modulus. (d), (e), (f) Same as in (a)-(c), but for a real backscattering.

respectively. Figure 4c and Fig. 4f show the corresponding maxima lines. Ridges of highest correlation and anticorrelation coefficients propagate to the finest scale at the base and top of each particle layer, as well as at the location of the maximum backscatter.

Hence each ridge shown in Fig. $4 c$ is associated with a discontinuity of the $P(r, t)$ signal. The value $M_{\text {CWT }}\left(i_{\text {ridges }}\right)$ of the average CWT coefficients along this ridge allows us to discriminate a backscatter peak from a layer base or top as

$M_{\mathrm{CWT}}\left(i_{\text {ridges }}\right)=\left.\overline{\mathrm{CWT}}_{a, b}(r, t)\right|_{a, b \in i_{\text {ridges }}}\left\{\begin{array}{l}>0 \text { : layer peak } \\ <0 \text { : layer base or top. }\end{array}\right.$

For each identified backscatter peak, the base (top) of the same layer can be found by looking for the first base (top) detected below (above). If the top of one layer is the base of the next one, the STRAT algorithm is designed to link these two layers into a single one with a peak defined as the maximum $P$ value of the two original peaks.

Finally, we apply a threshold value $R_{\mathrm{thr}}$ on the difference of backscatter power between peak height and base height defined as

$$
R=P\left(r_{\text {peak }}\right)-P\left(r_{\text {base }}\right)>R_{\text {thr }}
$$

This threshold removes overdetections that are due to noise variations such as the discontinuities detected be- tween points 200 and 350 shown in Fig. 4f. The $R_{\text {thr }}$ threshold implemented in the STRAT algorithm is derived with respect to the noise level $\sigma(t)$ as

$$
R_{\mathrm{thr}}=T_{3} \sigma(t),
$$

where $T_{3}$ is the particle layer threshold coefficient.

\section{2) Threshold DEtermination}

As this threshold is used to identify false peak/base detections in layers with low backscatter signal (i.e., molecular layers), we use $\sigma_{P=0}(r, t)$ as a substitute for $\sigma(r, t)$.

A PDF of $R(r, t) / \sigma(t)$ values is derived from the LNA database (10 profiles per day) to determine $R_{\mathrm{thr}}$. The PDF is shown in Fig. 5. Because of noise-related signal variations, discontinuities can also be detected in molecular layers, but corresponding $R(r, t)$ values are smaller than for particle layers. The PDFs of $R(r, t) / \sigma(t)$ values for discontinuities identified in molecular layers are also represented in Fig. 5 (solid line). This curve is obtained by processing simulated noisy molecular profiles derived from radiosonde data. The distribution is divided in two separate regions. The Gaussian distribution between 0 and 10 that contains $86 \%$ of the detections is due to noise variations. This effect corresponds to the many short CWT ridge lines shown in Fig. 4f. Values $R(r, t) / \sigma(t)$ for true particle layers are logically greater. Picking a threshold value $R_{\mathrm{thr}}$ of $10 \sigma(t)$ allows us to remove overdetections. 


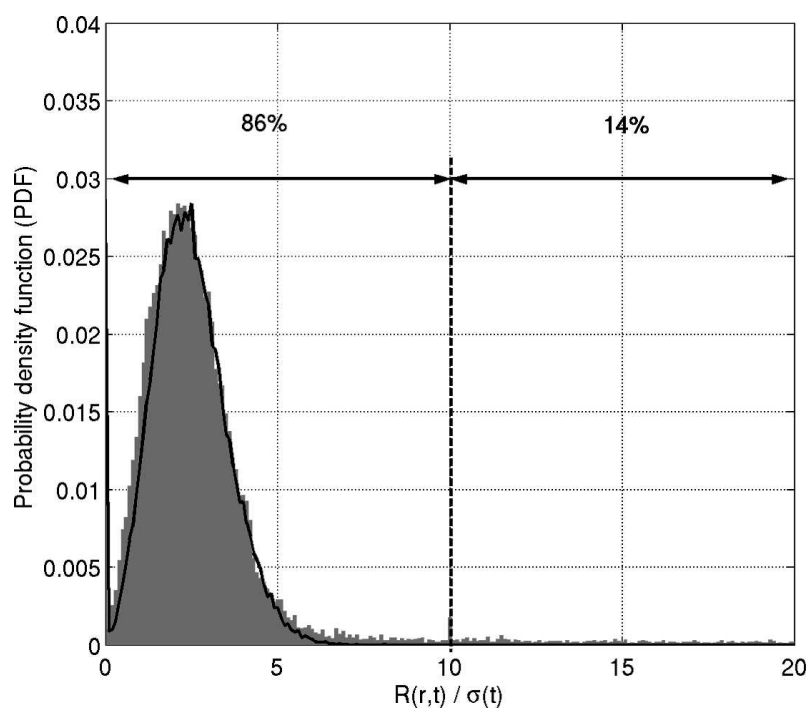

FIG. 5. PDF of $R(r, t) / \sigma(t)$ values estimated on 10 profiles per day for all the database, and PDF of simulated $R(r, t) / \sigma(t)$ values in molecular layers (solid line).

\section{d. Cloud and aerosol distinction}

\section{1) METHOD}

Aerosol and cloud layers can have similar signatures in lidar backscatter profiles. However, for near-IR, IR, visible, and UV wavelengths, the lidar backscatter power is generally greater for liquid water and optically thick ice for clouds than for aerosols. The cloud and aerosol distinction algorithm is based on the study by Wang and Sassen (2001), who applied a threshold on the peak $\operatorname{Pr}^{2}$ to the base $\mathrm{Pr}^{2}$ ratio. The ratio is expressed as

$$
d \operatorname{Pr}^{2}=\frac{P\left(r_{\text {peak }}, t\right) r_{\text {peak }}^{2}}{P\left(r_{\text {base }}, t\right) r_{\text {base }}^{2}} .
$$

Ratios greater (less) than a threshold $T_{4}$ classify a layer as cloud (aerosols). Figure 6a shows a 7-h time series of 532-nm backscatter power profiles. The measurements show significant backscatter between the ground and $2500 \mathrm{~m}$. After 1130 UTC one can see several occurrences of very strong extinction that are characteristic of dense water clouds. Figure $6 \mathrm{~b}$ shows profile-by-profile $d \mathrm{Pr}^{2}$ ratios for the areas identified as particle layers. It reveals a large profile-by-profile variability of $d \mathrm{Pr}^{2}$ values.

To improve this method, we derive average $d \mathrm{Pr}^{2}$ values for a given object (cloud or aerosol layer). To obtain this averaged value on a vertically and temporally consistent particle layer, range-time processing is required.

An average $d P r_{\text {layer }}^{2}$ value is computed for each identified particle layer, and the $T_{4}$ threshold is applied to this average value to separate cloud from aerosol layers as

$$
\left\{\begin{array}{l}
d P r_{\text {layer }}^{2}>T_{4}, \text { then layer is cloud layer } \\
d P r_{\text {layer }}^{2}<T_{4}, \text { then layer is aerosol layer. }
\end{array}\right.
$$

Figure $6 \mathrm{c}$ shows the $d P r_{\text {layer }}^{2}$ values for cloud and aerosol layers observed on 26 May 2003. Some particle layers appear with significantly stronger $d P r_{\text {layer }}^{2}$ than others.

\section{2) Threshold DETERMinATION}

The PDFs of $d P r_{\text {layer }}^{2}$ values are shown in Fig. 7 for three different vertical range intervals. The distribution based on the complete vertical range $(0-15 \mathrm{~km})$ is represented by a solid line, the distribution of $d P r_{\text {layer }}^{2}$ for layers below $7.5 \mathrm{~km}$ is shown in the dashed line with square markers, and the distribution of $d P r_{\text {layer }}^{2}$ for layers above $7.5 \mathrm{~km}$ is drawn with a dashed line and diamond markers. Those intervals of altitude are used because except for exceptional events like volcanic eruptions; we assume that aerosol concentrations are not sufficient to be detected above $7.5 \mathrm{~km}$, whereas cloud layers extend from 0 to $15 \mathrm{~km}$. So distributions of values $d P r_{\text {layer }}^{2}$ are due to different contributions: under $7.5 \mathrm{~km}$ a combination of cloud and aerosol contributions, and above $7.5 \mathrm{~km}$ only cloud contributions. Thus, the distribution of $d P r_{\text {layer }}^{2}$ for aerosol layers is located between 1 and 4 where the two dashed lines are distinct whereas the distribution of $d P r_{\text {layer }}^{2}$ for cloud layers is wider. To separate cloud from aerosol layers based on these distributions, we select a threshold value $T_{4}=4$. So Eq. (18) becomes

$$
\left\{\begin{array}{l}
d P r_{\text {layer }}^{2}>4, \text { then layer is cloud layer } \\
d P r_{\text {layer }}^{2}<4, \text { then layer is aerosol layer, }
\end{array}\right.
$$

for particle layers below $7.5 \mathrm{~km}$. Above $7.5 \mathrm{~km}$ we assume that $100 \%$ of particle layers corresponds to clouds.

\section{e. Boundary layer height detection}

\section{Method}

The atmospheric boundary layer (ABL) is the lowest part of the troposphere that is directly influenced by the earth's surface and responds on short time scales to surface forcing. This is the region that is well mixed due to convectively driven mixing. Several BLH detection methods are described in the literature. Methods using a simple signal threshold (e.g., Melfi et al. 1985; Boers et al. 1988) are not appropriate for cases with varying aerosol extinction. Methods based on gradient properties at the top of the boundary layer (e.g., Flamant et al. 1997) need averaged or smoothed signals and hence lose resolution. In the presence of boundary layer clouds, all methods, including wavelet analysis methods (e.g., Cohn and Angevine 2000; Brooks 2003), are likely 
(a)

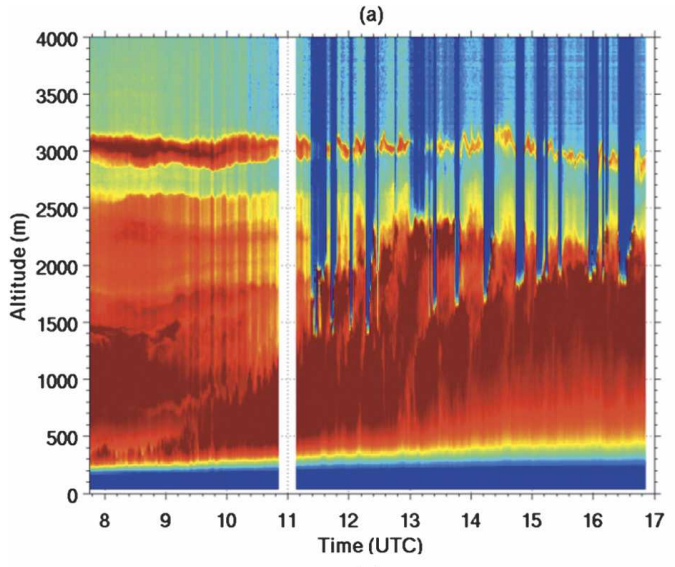

(c)

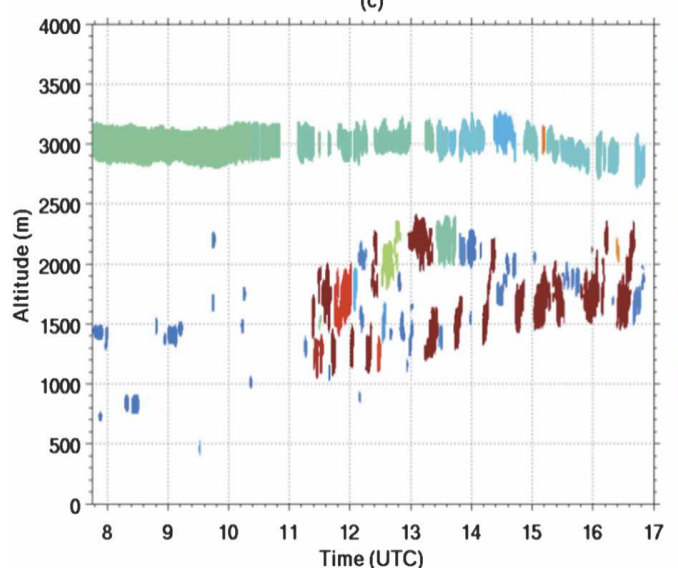

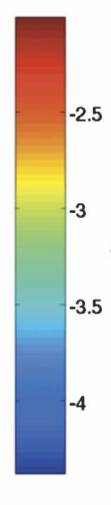

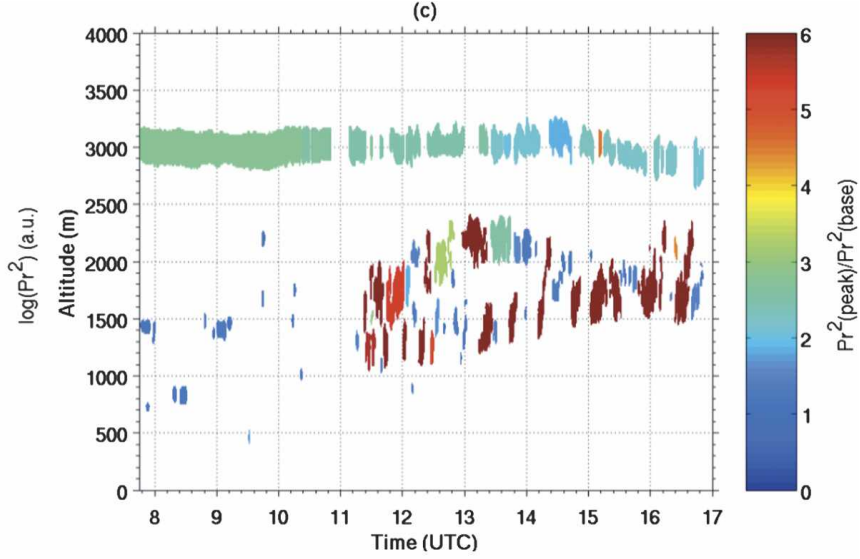

(d)
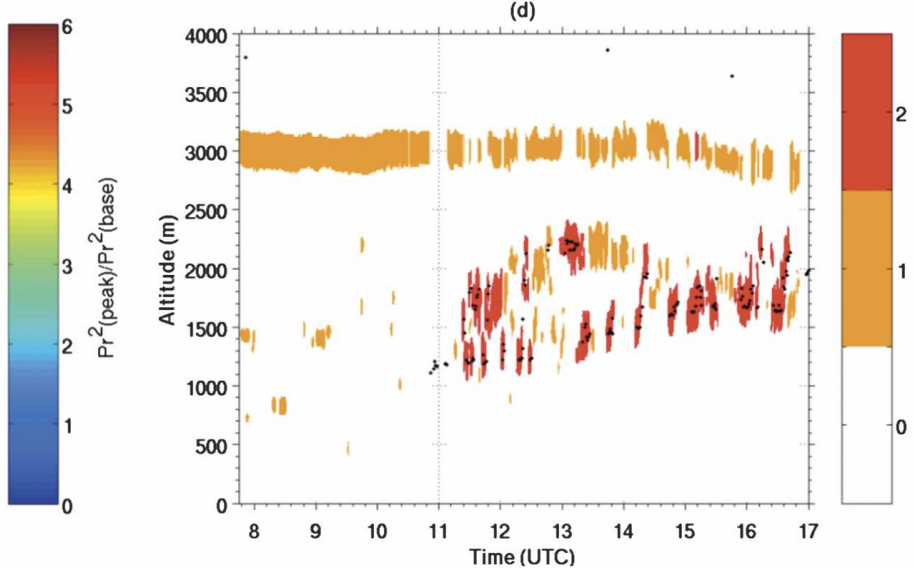

FIG. 6. (a) LNA data 532-nm WFOV telescope on 26 May 2003, (b) profile-by-profile $d P r_{2}^{2}$ ratio (17), (c) layer-by-layer $d P r_{\text {layer }}^{2}$ ratio, and (d) flag obtained with particle layer distinction; cloud layers are in red, and aerosol layers are in orange (18). Ceilometer CTH detections are represented with black points.

to identify the top of the cloud as BLH because the strongest gradient (or correlation) will occur in that part of the profile. In the STRAT algorithm we use the output of the molecular layer module and particle layer module to help distinguish the low-altitude clouds from the boundary layer below them. The boundary layer height detection method used in the STRAT algorithm, is similar to the particle layers detection method described in section 3c. It is inspired by the work of Mallat and Hwang (1992) and Brooks (2003).

The wavelet used here is the first derivative of a Gaussian $\Psi^{\prime}(r)$, shown in Fig. 8 because its shape is very similar to the negative gradient of the backscatter signal at the top of the boundary layer during daytime. A standard boundary layer backscatter signal is shown in Fig. 9a. As for particle layer detections, the CWT is computed for each $P(r, t)$ profile as

$$
\mathrm{CWT}_{a, b}^{\prime}(r, t)=\sum_{r} P(r, t) \psi_{a, b}^{\prime}(r)
$$

where

$$
\Psi_{a, b}^{\prime}(r)=\frac{1}{\sqrt{a}} \Psi^{\prime}\left(\frac{r-b}{a}\right)
$$

Here, $a$ is the wavelet dilation (or scale) and $b$ is the location of its center.

Then modulus maxima lines of the $\mathrm{CWT}_{a, b}^{\prime}(r, t)$ are also determined to detect all gradients in the backscatter signal. Because of the wavelet shape, negative gradients can be discriminated from positive ones using average values of the $\mathrm{CWT}^{\prime}$ coefficients along this ridge as follows:

$$
M_{\mathrm{CWT}}^{\prime}\left(i_{\text {ridges }}\right)={\overline{\mathrm{CWT}_{a, b}^{\prime}(r, t)}}_{a, b \in i_{\text {ridges }}}\left\{\begin{array}{l}
<0 \text { : positive gradient } \\
>0 \text { : negative gradient }
\end{array}\right.
$$




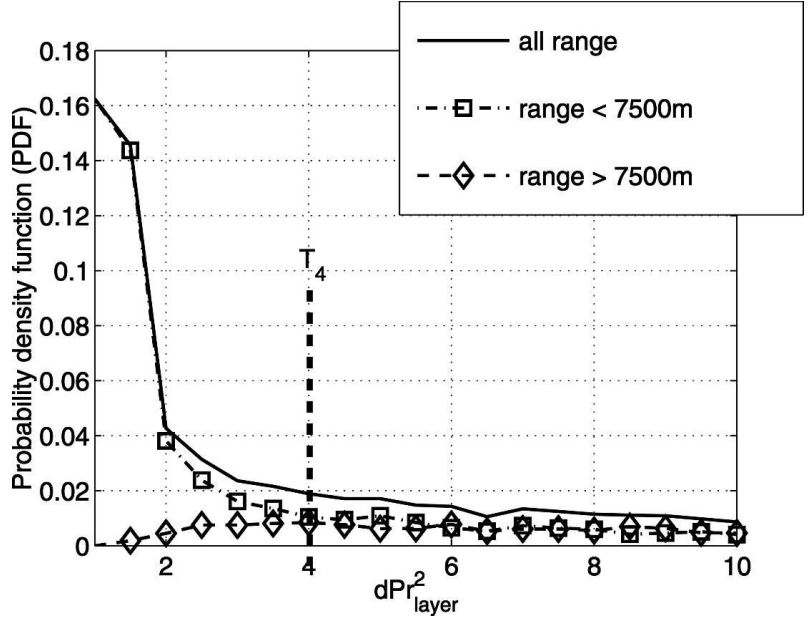

FIG. 7. PDF of $d P r_{\text {layer }}^{2}$ values estimated on the entire database for all the range (solid line), range below $7.5 \mathrm{~km}$ (dashed line with squares), and range above $7.5 \mathrm{~km}$ (dashed line with diamonds).

The detection of negative gradients combined with the altitude of the lowest molecular range, $H_{\text {min_mol }}$ (shown in Fig. 9), and the base height of the lowest particle layer $\left(H_{\text {min_part }}\right)$ allows us to estimate the boundary layer height. Four different cases, illustrated in Figs. 9a,c,e, must be considered:

- if $H_{\text {min_mol }}<H_{\text {min_part }}$ (molecular layer below the lowest identified particle layer),

- there exists a ridge with $M_{\mathrm{CWT}}^{\prime}<0$ that propagates up to a range $r<H_{\text {min_mol: }}$ BLH is the range $r$ (if there is more than one ridge, only the ridge with the minimum $M_{\text {CWT }}^{\prime}$ value is kept). This case is illustrated in Fig. 9a with an example of a standard lidar backscatter signal and in Fig. 9b with the corresponding wavelet coefficients.

- there does not exist a ridge with $M_{\mathrm{CWT}}^{\prime}<0$ that

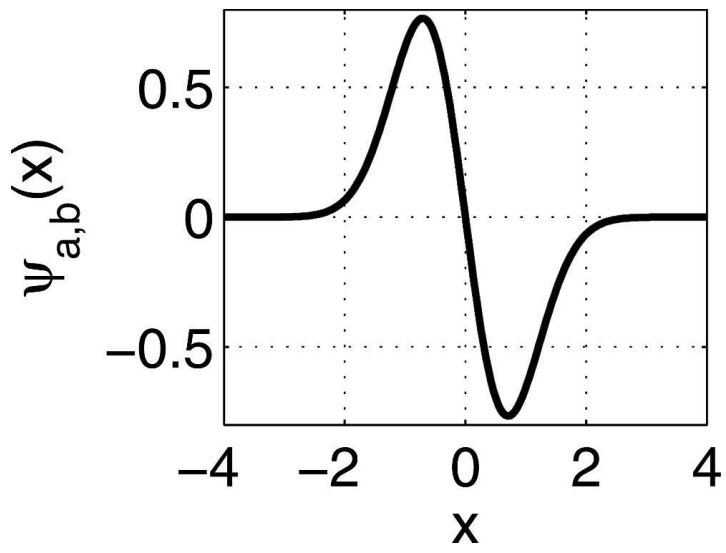

FIG. 8. First derivative of a Gaussian wavelet.
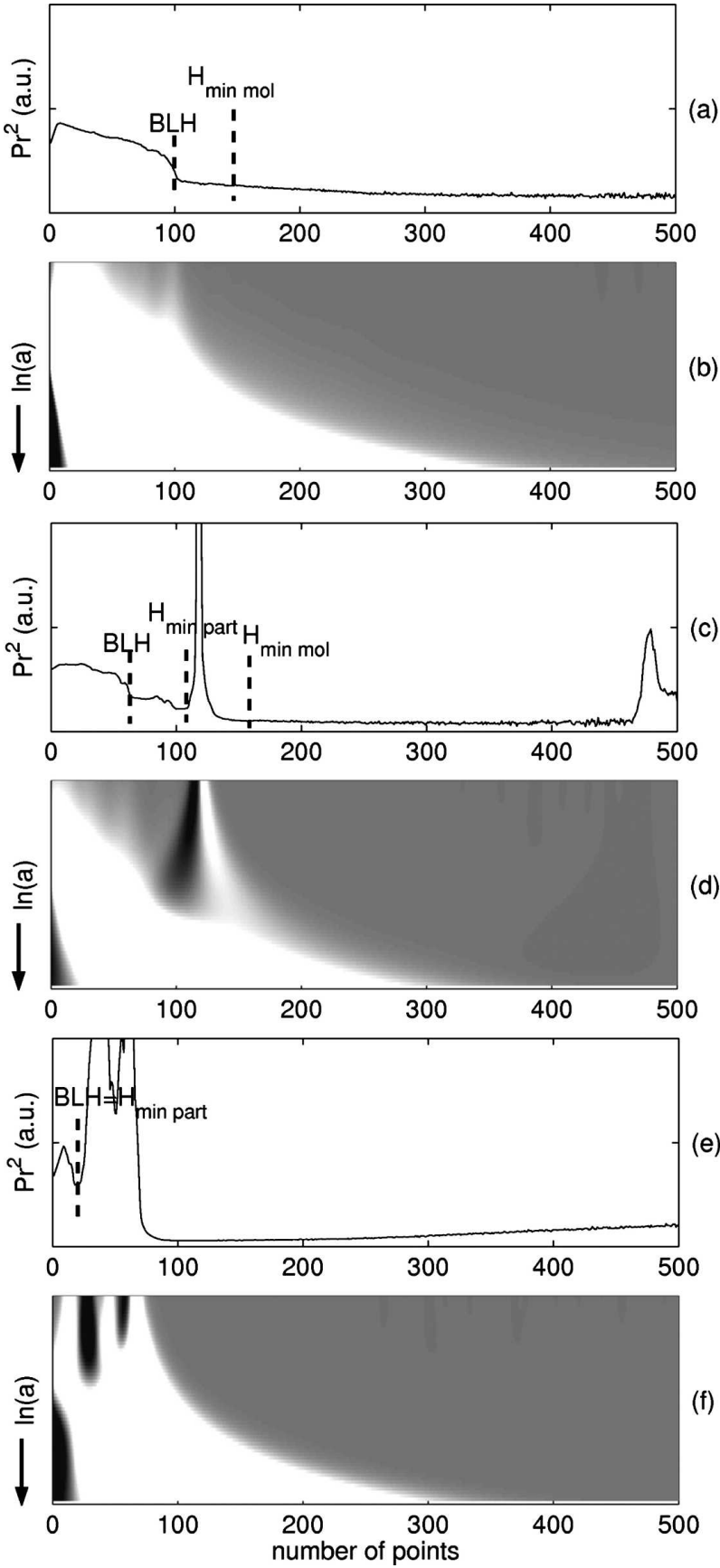

FIG. 9. (a), (c), (e) Not-normalized, range-corrected backscattered signal; (b), (d), (f) corresponding CWT coefficients calculated for different dilation $a$ (finest high up) and different location of wavelet's center $b$ with highest coefficients in white and lowest in black. (a), (b) A clear case, (c), (d) a cloudy case with a cloud near the BL, and (e), (f) a cloudy case with a cloud at the BL.

propagates up to a range $r<H_{\text {min_mol: }}$ : $\mathrm{BLH}$ is undefined.

- if $H_{\text {min_part }}<H_{\text {min_mol }}$ (molecular layer above the lowest identified particle layer), 
TABLE 2. Parameters of the STRAT algorithm to process LNA data.

\begin{tabular}{lccccc}
\hline \hline & Noise detection & $\begin{array}{c}\text { Molecular layer } \\
\text { detection }\end{array}$ & $\begin{array}{c}\text { Cloud and aerosol } \\
\text { detection }\end{array}$ & $\begin{array}{c}\text { Cloud and aerosol } \\
\text { distinction }\end{array}$ & $\begin{array}{c}\text { Boundary layer height } \\
\text { detection }\end{array}$ \\
\hline $\begin{array}{l}\text { Threshold } \\
\text { Window length }\end{array}$ & $\begin{array}{c}T_{1}=3 \\
\text { gates or } 75 \mathrm{~m}\end{array}$ & $\begin{array}{c}T_{2}=3 \\
\text { gates or } 315 \mathrm{~m}\end{array}$ & $T_{3}=10$ & $T_{4}=4$ & - \\
\hline
\end{tabular}

- there exists a ridge with $M_{\mathrm{CWT}}^{\prime}<0$ that propagates up to a range $r<H_{\text {min_part }}$ : BLH is the range $r$ (if there is more than one ridge, only the ridge with the minimum $M_{\text {CWT }}^{\prime}$ value is kept). A cloud or aerosol layer is located near the top of the BL. This case is illustrated in Fig. 9c with an example of a backscatter signal where the molecular layer is above the lowest identified particle layer. Figure $9 \mathrm{~d}$ shows the corresponding wavelet coefficients.

- there does not exist a ridge with $M_{\mathrm{CWT}}^{\prime}<0$ that propagates up to a range $r<H_{\text {min_part }}$ : BLH is $H_{\text {min_part }}$. A cloud or aerosol layer is located at the top of the BL. This case is illustrated in Fig. 9e with an example of a backscatter signal where a cloud layer is present at the top of the BL. Figure $9 f$ shows the corresponding wavelet coefficients.

After daytime convection ceases, aerosol layers become stratified and multiple layers can form near the surface (boundary and residual layers). In such situations, the STRAT algorithm is not able to distinguish the top of the boundary layer and the top of the residual layer.

\section{Evaluation of the STRAT algorithm}

\section{a. Evaluation of the molecular layer detection}

Here we evaluate if layers identified by STRAT as molecular layers contain any additional extinction due to the presence of some quantity of aerosols. To do so we apply a classic approach of optical thickness estimation (Platt 1979) that is based on the ratio of the lidar power attenuation from the base to the top of the molecular layer to a theoretical molecular attenuation. Analysis of $4 \mathrm{yr}$ of SIRTA lidar profiles containing molecular layers extending more than $1 \mathrm{~km}$ reveals that these layers exhibit attenuation uncertainties of $\pm 2.10^{-5} \mathrm{~m}^{-1}$ in terms of equivalent extinction. Hence the parameters used in the molecular layer detection module (see Table 2) imply that STRAT will allow layers whose attenuation is somewhat different from that of theoretical molecular layers to be identified as particle free. As a result such layers could contain up to 2 $\times 10^{-5} \mathrm{~m}^{-1}$ particle extinction, equivalent to a 0.02 optical depth for a 1-km-deep layer. This uncertainty can be reduced either by increasing the test range (e.g., from 300 to $500 \mathrm{~m}$ ) or by reducing the variability threshold $\left(T_{2}\right)$.

\section{b. Cloud and aerosol layer detection}

\section{1) Performance evaluation based on SIMULATED DATA}

Figure 10 shows results obtained by the STRAT algorithm cloud and aerosol layer detection with a simulated backscatter profile containing a cloud (Fig. 10a). Two slopes $S_{1}$ and $S_{2}$ are used to describe the majority of cases, where $S_{1}$ is the molecular slope and $S_{2}$ is the slope of the backscatter profile in the cloud between the base and the peak. Figures 10b,c illustrate results obtained on $\mathrm{CBH}$ and cloud-top height $(\mathrm{CTH})$ detection, respectively. We describe results obtained for slopes between $-0.5 \times 10^{-10}$ and $-2 \times 10^{-10}\left(\mathrm{~m}^{-1}\right.$ $\mathrm{sr}^{-1}$ ) $\mathrm{m}^{-1}$ for $S_{1}$ and between $1 \times 10^{-8}$ and $7 \times 10^{-8}$ for $S_{2}$. The CBH detection is sensitive to both slopes, but the maximum resulting error is -3 gates $(-45 \mathrm{~m}$ for LNA profiles). CTH detection depends on the slope of backscatter in the particle layer. CTH errors are biased high between 0 and 5 gates ( 0 to $75 \mathrm{~m}$ for LNA data) for the largest $S_{2}$ values.

\section{2) Comparison With Retrievals From CEILOMETER}

We compare cloud-base height retrievals derived by applying STRAT to LNA data to those derived by a Vaisala ceilometer located nearby $(100 \mathrm{~m})$. Figure 11a shows the PDF of cloud-base height for the two systems based on 12 months of observation. We limit our comparisons to situations where each retrieval is consistent for $10 \mathrm{~min}$. We note that the LNA misses clouds below $1300 \mathrm{~m}$, due to the large overlap function. Above 5000 $\mathrm{m}$, the ceilometer data become unreliable due to limited power. Comparisons of cloud and cloud-free occurrence detections by the two systems for the 13005000-m vertical range are shown in Table 3. In situations labeled as cloud free by the ceilometer, we find $92 \%$ agreement, and $8 \%$ cloud detection by LNA/ STRAT. In situations where the ceilometer detects a cloud between 1300 and $5000 \mathrm{~m}$, LNA/STRAT detects a particle layer $93 \%$ of the time with $74 \%$ clouds and $19 \%$ aerosols. The cloud-versus-aerosol discrepancy 

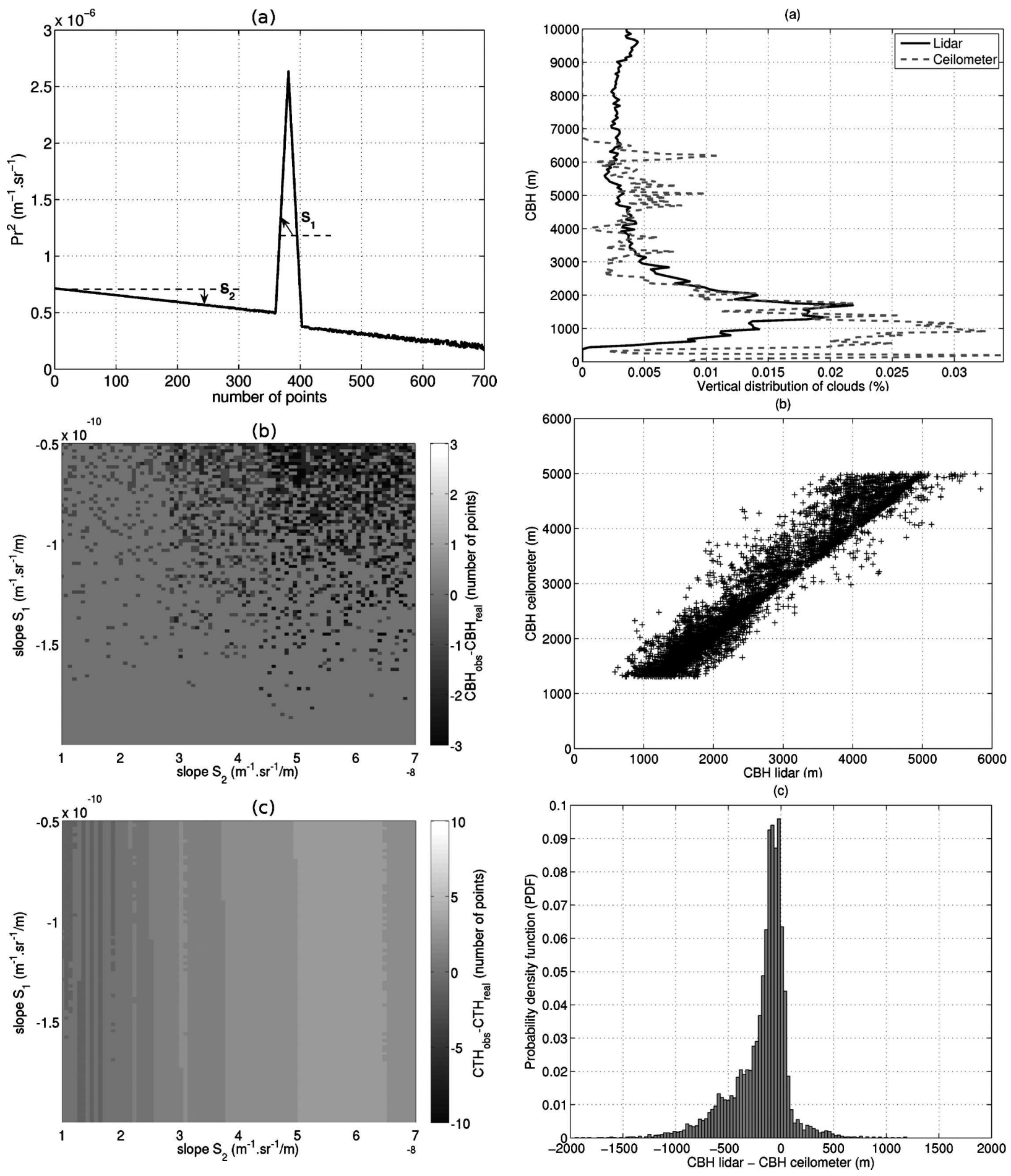

FIG. 10. (a) Simulated backscattered profile with an added noise, where $S_{1}$ and $S_{2}$ are two slopes that allow us to describe this profile. (b) Difference between detected CBH by STRAT and the real CBH. (c) Difference between detected CTH by STRAT and the real CTH.

FIG. 11. (a) Vertical distribution of clouds seen by the LNA (dark line) and the Vaisala ceilometer (gray dashed line). (b) Scatterplot of $\mathrm{CBH}$ detected by STRAT algorithm on 532-nm NFOV telescope data and $\mathrm{CBH}$ determined with ceilometer data. (c) $\mathrm{PDF}$ of $\mathrm{CBH}_{\text {lidar }}-\mathrm{CBH}_{\text {ceilometer }}$. 
TABLE 3. Comparison between STRAT detection and ceilometer detection. The asterisk denotes cloud and aerosol free.

\begin{tabular}{cccc}
\hline \hline LNA lidar ceilometer & Cloud free* & Cloud & Aerosol \\
\hline No detection & 92 & 8 & - \\
Cloud & 7 & 74 & 19 \\
\hline
\end{tabular}

can result from the simple cloud/aerosol threshold used in STRAT as well as possible aerosol detection by the 855-nm ceilometer. Next we compare $\mathrm{CBH}$ retrieved by both systems when they agree that a cloud is present in the 1300-5000-m range. Figure $11 \mathrm{~b}$ shows a scatterplot of LNA CBH versus ceilometer CBH and Fig. 11c shows the PDF of the difference between the two retrievals, based on 12 months of observation. The VAISALA CBH detection method (Vaisala proprietary algorithm) is based on the detection of high backscatter in the profile, so the retrieved $\mathrm{CBH}$ is frequently placed between the base of the cloud and the altitude of maximum backscatter in the cloud. The position of the ceilometer $\mathrm{CBH}$ in the lidar backscatter is illustrated in Fig. 12. The mean difference between LNA/STRAT and ceilometer $\mathrm{CBH}$ is $-178 \mathrm{~m}$, which is consistent with the result of Fig. 12. The standard deviation of the comparison is $265 \mathrm{~m}$. The PDF can be divided into three zones: zone 1 contains $80 \%$ of detections and gathers the situations with most consistent retrievals, zone 2 includes $5 \%$ of the situations for which ceilometer CBHs are lower than corresponding STRAT retrievals, and zone 3 contains $14 \%$ of the distribution for which STRAT retrievals are lower than the ceilometer CBH.

\section{c. Boundary layer height detection and comparison with radiosounding retrievals}

Figure 13 shows a comparison of the BLH estimated from radiosoundings (launched every day at 1200 UT $15 \mathrm{~km}$ from SIRTA) and BLH processed by the STRAT algorithm on LNA data. The method used to extract BLH from soundings is a threshold method applied on the Richardson number $R_{i b}(z)$ (Menut et al. 1999), calculated as

$$
R_{i b}(z)=\frac{g\left(z-z_{0}\right)}{\theta(z)} \frac{\left[\theta(z)-\theta\left(z_{0}\right)\right]}{u(z)^{2}+v(z)^{2}},
$$

where $\theta$ is the potential temperature, $g$ is the acceleration due to gravity, $z$ is the height, $z_{0}$ is height of the surface, and $u$ and $v$ are the zonal and meridian wind components. The BLH is estimated with a threshold value of 0.21 (Vogelezang and Holtslag 1996). The lidar-derived BLH is the median BLH extracted between $t_{0}$ and $t_{0}+5^{\prime}$ (Menut et al. 1999), where $t_{0}$ is the radiosonde launch time.

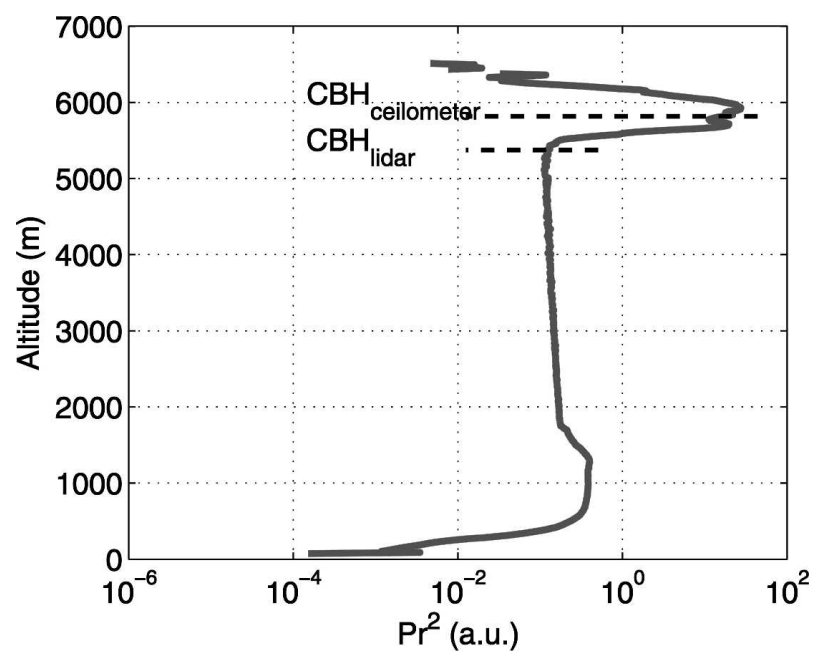

FIG. 12. $\mathrm{CBH}_{\text {lidar }}$ estimated on the range-corrected backscattered profile (dark solid line) and the corresponding $\mathrm{CBH}_{\text {ceilometer }}$.

We study 200 temporally and spatially collocated radiosonde (RS) and lidar profiles; 125 situations correspond to clear-sky events without clouds below $5000 \mathrm{~m}$ and without aerosol layers above the boundary layer in a 20-min window around the RS launch. The mean difference between lidar and RS-derived BLH estimates is $99 \mathrm{~m}$ with a standard deviation $\sigma$ of $452 \mathrm{~m}$, hence the standard error in the mean is $62 \mathrm{~m}$ for a $95 \%$ confidence interval. We find that $83 \%$ of the population is within $\pm 500 \mathrm{~m}$ (close to $1 \sigma)$.

We assume that points beyond $\pm 500 \mathrm{~m}$ are outliers and restrict the comparison to situations when the difference is in the interval $[-500 \mathrm{~m},+500 \mathrm{~m}]$, the mean difference becomes $21 \mathrm{~m}$, the standard deviation is 200 $\mathrm{m}$, and the standard error is $30 \mathrm{~m}$. When we further restrict the comparison to clear-sky situations, we find very similar statistics (see Table 4). The population of BLH differences contains two subgroups, one representing $83 \%$ of the situations where BLH retrievals agree within $20 \mathrm{~m} \pm 30 \mathrm{~m}$ (95\% confidence) and the other (17\% of the population) representing cases with very large discrepancies (between 500 and $1500 \mathrm{~m}$ ). The inconsistency between the two retrieval methods can be due to lack of mixing or entrainment of aerosols, or poor collocation of radiosonde and lidar profiles. Table 4 shows that the presence of cloud does not introduce additional discrepancies.

\section{Conclusions}

The STRAT algorithm has been developed to analyze large datasets of lidar backscatter profile and to retrieve the vertical structure of particle layers in the 
(a)

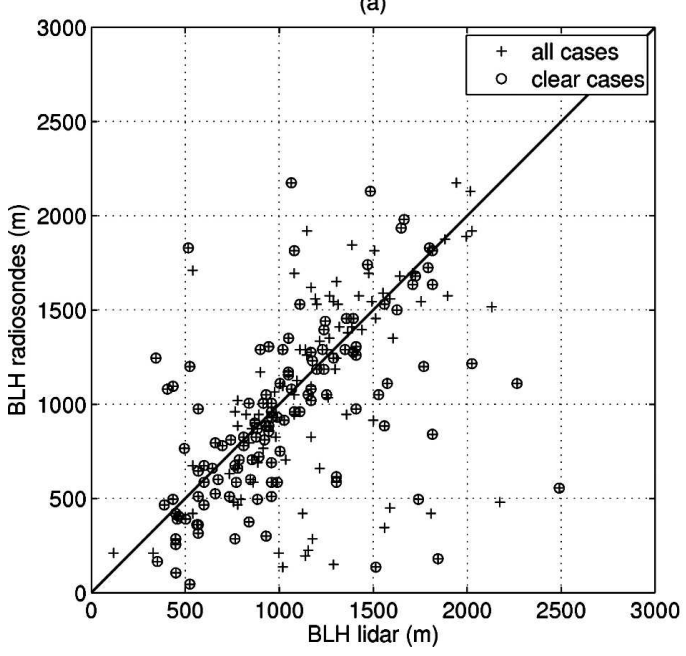

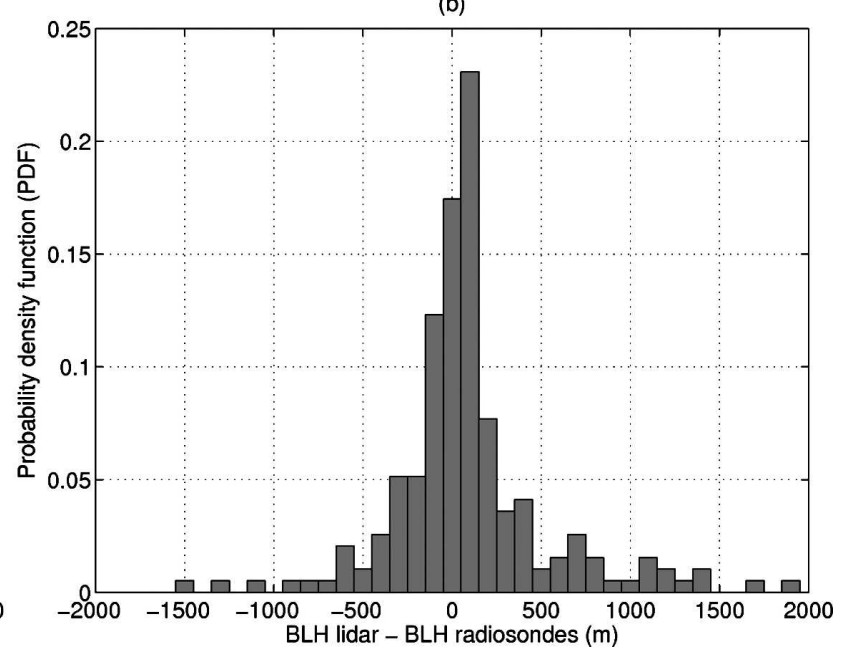

FIG. 13. (a) Scatterplot of BLH retrieved by STRAT algorithm on 532-nm NFOV telescope data and BLH estimated by radiosondes, for all cases with cross markers and for clear cases with ring markers. (b) $\mathrm{PDF}$ of $\mathrm{BLH}_{\text {lidar }}-\mathrm{BLH}_{\text {radiosondes }}$ for all cases.

atmosphere. The algorithm is based on four successive detections carried out on individual profiles. The signal noise level is a key parameter in the algorithm as the detection thresholds at each step of the process are determined with respect to it. Hence the algorithm automatically adjusts to varying levels of signal noise. Molecular or (near) particle-free layers are determined with a conservative approach to minimize false detections so that those layers can effectively be used for automated normalization processes. Identification of particle layers is done by using continuous wavelet transforms to identify discontinuities in the lidar profile and choosing those that effectively correspond to cloud or aerosol layer boundaries. We find good consistency between cloud-base heights retrieved by STRAT and those provided by a commercial ceilometer analysis. The height uncertainty inherent to the method is evaluated to be less than 3 times the vertical resolution (e.g., less than $45 \mathrm{~m}$ for the LNA). Similarly, the transition from the boundary layer to the free troposphere is ana-

TABLE 4. Comparison between STRAT BLH retrievals and BLH estimated by radiosondes.

\begin{tabular}{|c|c|c|c|c|}
\hline Situations & All & $\begin{array}{l}\text { Clear } \\
\text { sky }\end{array}$ & $\begin{array}{c}\text { All } \\
( \pm 500 \mathrm{~m})\end{array}$ & $\begin{array}{l}\text { Clear sky } \\
( \pm 500 \mathrm{~m}\end{array}$ \\
\hline No. of cases & 211 & 125 & 173 & 105 \\
\hline $\begin{array}{l}\text { Mean }\left(\mathrm{BLH}_{\text {lidar }}-\mathrm{BLH}_{\mathrm{RS}}\right) \\
\quad(\mathrm{m})\end{array}$ & 99 & 89 & 24 & 51 \\
\hline $\begin{array}{l}\text { Std dev }\left(\mathrm{BLH}_{\text {lidar }}-\mathrm{BLH}_{\mathrm{RS}}\right) \\
\quad(\mathrm{m})\end{array}$ & 452 & 445 & 202 & 199 \\
\hline $\begin{array}{l}\text { Standard error of the mean } \\
\left(\mathrm{BLH}_{\text {lidar }}-\mathrm{BLH}_{\mathrm{RS}}\right)(\mathrm{m}) \\
(95 \% \text { confidence interval })\end{array}$ & 62 & 80 & 30 & 38 \\
\hline
\end{tabular}

lyzed with wavelet transforms. When compared to boundary layer heights retrieved from radiosondes, we find no significant bias in the STRAT retrievals, but the comparison reveals a large scatter due to the inconsistency between the aerosol-based and the thermodynamic-based BLH definition. Even though a few test cases have been carried out with the STRAT algorithm on 355-, 532-, and 1064-nm lidar systems, with both analog and photon-counting detection systems, the true portability of the STRAT algorithm to diverse large lidar datasets is still under study.

Acknowledgments. This work has been carried out with the financial support of the French National Space Agency CNES. The authors would like to acknowledge Stéphane Mallat for stimulating discussions on our application of the CWT method. We extend our acknowledgments to the reviewers for their comprehensive reviews and useful input.

\section{REFERENCES}

Boers, R., J. D. Spinhirne, and W. D. Hart, 1988: Lidar observations of the fine-scale variability of marine stratocumulus clouds. J. Appl. Meteor., 27, 797-810.

Bösenberg, J., and Coauthors, 2003: EARLINET: A European Aerosol Research Lidar Network to Establish an Aerosol Climatology. MPI Rep. 348, Max-Planck-Institut für Meteorologie, Hamburg, Germany, 192 pp.

Brooks, I. M., 2003: Finding boundary layer top: Application of a wavelet covariance transform to lidar backscatter profiles. $J$. Atmos. Oceanic Technol., 20, 1092-1105.

Cadet, B., L. Goldfarb, D. Faduilhe, S. Baldy, V. Giraud, P. Keckhut, and A. Réchou, 2003: A sub-tropical cirrus clouds climatology from Reunion Island $\left(21^{\circ} \mathrm{S}, 55^{\circ} \mathrm{E}\right)$ lidar data set. Geophys. Res. Lett., 30, 1130, doi:10.1029/2002GL016342. 
V. Giraud, M. Haeffelin, P. Keckhut, A. Rechou, and S. Baldy, 2005: Improved retrievals of cirrus cloud optical properties using a combination of lidar methods. Appl. Opt., 44, $1726-1734$.

Chazette, P., J. Pelon, and G. Mégie, 2001: Determination by spaceborne backscatter lidar of the structural parameters of atmospheric scattering layers. Appl. Opt., 40, 3428-3440.

Chiriaco, M., H. Chepfer, V. Noel, A. Delaval, M. Haeffelin, P. Dubuisson, and P. Yang, 2004: Improving retrievals of cirrus cloud particle size coupling lidar and three-channel radiometric techniques. Mon. Wea. Rev., 132, 1684-1700.

Clothiaux, E. E., G. Mace, T. Ackerman, T. Kane, J. Spinhirne, and V. Scott, 1998: An automated algorithm for detection of hydrometeor returns in micropulse lidar data. J. Atmos. Oceanic Technol., 15, 1035-1042.

Cohn, S. A., and W. M. Angevine, 2000: Boundary-layer height and entrainment zone thickness measured by lidars and windprofiling radars. J. Appl. Meteor., 39, 1233-1247.

Comstock, J. M., T. P. Ackerman, and G. G. Mace, 2002: Groundbased lidar and radar remote sensing of tropical cirrus clouds at Nauru Island: Cloud statistics and radiative impacts. $J$. Geophys. Res., 107, 4714, doi:10.1029/2002JD002203.

Durieux, E., and L. Fiorani, 1998: Measurement of the lidar signal fluctuation with a shot-per-shot instrument. Appl. Opt., 37, 7128-7131.

Flamant, C., J. Pelon, P. H. Flamant, and P. Durand, 1997: Lidar determination of the entrainment zone thickness at the top of the unstable marine atmospheric boundary layer. Bound.Layer Meteor., 83, 247-284.

Haeffelin, M., and Coauthors, 2005: SIRTA, a ground-based atmospheric observatory for cloud and aerosol research. Ann. Geophys., 23, 253-275.

Hodzic, A., and Coauthors, 2004: Comparison of aerosol chemistry transport model simulations with lidar and Sun photometer observations at a site near Paris. J. Geophys. Res., 109, D23201, doi:10.1029/2004JD004735.

Hoff, R. M., and K. J. McCann, 2002: A Regional East Atmospheric Lidar Mesonet (REALM). Eos, Trans. Amer. Geophys. Union, 83 (Fall Meeting Suppl.), A22C-0147.

Mallat, S. G., and W. L. Hwang, 1992: Singularity detection and processing with wavelets. IEEE Trans. Inf. Theory, 38, 617643.

Mathieu, A., J.-M. Piriou, M. Haeffelin, P. Drobinski, F. Vinit, and F. Bouyssel, 2006: Identification of error sources in convective planetary boundary layer cloud forecast using SIRTA observations. Geophys. Res. Lett., 33, L19812, doi:10.1029/ 2006GL026001.

Melfi, S. H., J. D. Sphinhirne, S. H. Chou, and S. P. Palm, 1985: Lidar observations of the vertically organized convection in the planetary boundary layer over the ocean. J. Climate Appl. Meteor., 24, 806-821.

Menut, L., C. Flamant, J. Pelon, and P. H. Flamant, 1999: Urban boundary layer height determination from lidar measurements over the Paris area. Appl. Opt., 38, 945-954.

Naud, N., M. Haeffelin, P. Muller, Y. Morille, and A. Delaval, 2004: Assessment of MISR and MODIS cloud top heights through comparison with a back-scattering lidar at SIRTA. Geophys. Res. Lett., 31, L04114, doi:10.1029/2003GL018976.

Pal, S. R., W. Steinbrecht, and A. I. Carswell, 1992: Automated method for lidar determination of cloud base height and vertical extent. Appl. Opt., 34, 2388-2399.

Platt, C. M., 1979: Remote sounding of high clouds: I. Calculation of visible and infrared optical properties from lidar and radiometer measurements. J. Appl. Meteor., 18, 1130-1143.

- , and Coauthors, 1994: The Experimental Cloud Lidar Pilot Study (ECLIPS) for cloud-radiation research. Bull. Amer. Meteor. Soc., 75, 1635-1654.

Sassen, K., and J. R. Campbell, 2001: A midlatitude cirrus cloud climatology from the Facility for Atmospheric Remote Sensing. Part I: Macrophysical and synoptic properties. J. Atmos. Sci., 58, 481-496.

- M. Griffin, and G. Dodd, 1989: Optical scattering and microphysical properties of subvisual cirrus clouds, and climatic implications. J. Appl. Meteor., 28, 91-98.

Shimizu, A., and Coauthors, 2004: Continuous observations of Asian dust and other aerosols by polarization lidars in China and Japan during ACE-Asia. J. Geophys. Res., 109, D19S17, doi:10.1029/2002JD003253.

Vogelezang, D. H. P., and A. A. M. Holtslag, 1996: Evaluation and model impacts of alternative boundary-layer height formulations. Bound.-Layer Meteor., 81, 245-269.

Wang, Z., and K. Sassen, 2001: Cloud type and macrophysical property retrieval using multiple remote sensors. J. Appl. Meteor., 40, 1665-1682.

Welton, E. J., J. R. Campbell, J. D. Spinhirne, and V. S. Scott, 2001: Global monitoring of clouds and aerosols using a network of micro-pulse lidar systems. Proc. SPIE, 4153, 151-158.

Winker, D., J. Pelon, and P. McCormick, 2003: The CALIPSO mission: Spaceborne Lidar for observations of aerosols and clouds. Proc. SPIE, 4893, 1-11. 